\title{
Medial rectus muscle myositis as an atypical presentation of mucosa-associated lymphatic tissue lymphoma: a case report
}

\author{
Miosite do músculo reto medial como forma atípica de apresentação de linfoma tipo MALT: relato de caso
}

Juliana Sá Freire Medrado Dias ${ }^{1}$, Mirtha Alicia Ramirez Dittrich ${ }^{1}$, Jacqueline Martins de Sousa ${ }^{1}$, Luiz Fernando Teixeira ${ }^{1}$, Paulo Gois Manso ${ }^{1}$

\begin{abstract}
Here we describe the rare case of a 55-year-old man with medial rectus muscle myositis as an atypical presentation of non-Hodgkin B-cell mucosa-associated lymphoma (MALT). Pathology and immunohistochemistry of the affected muscle confirmed the diagnosis of a neoplasm. The primary etiology of orbital myositis is Graves' ophthalmopathy, but several other diseases may cause this clinical presentation. Therefore, the neoplastic causes must be eliminated from the differential diagnoses. Non-Hodgkin B-cell mucosa-associated lymphoma is the most common histological type of lymphoma in the orbit, with the conjunctiva and lacrimal glands being the most commonly affected sites. However, it may also present in atypical forms involving others sites and tissues.
\end{abstract}

Keywords: Orbital neoplasms; Orbital myositis; Oculomotor muscles/pathology; Muscle neoplasms; Orbital neoplasms; Lymphoma, B-Cell, marginal zone; Humans; Male; Middle-aged; Case report

\section{RESUMO}

Descrevemos um raro caso de miosite do músculo reto medial como forma atípica de apresentação de linfoma não-Hodgkin de células B tipo MALT. A anatomia patológica e imuno-histoquímica do músculo afetado confirmaramo diagnóstico definitivo do caráter neoplásico da doença. As miosites orbitárias têm como principal etiologia a oftalmopatia de Graves, porém diversas outras causas podem apresentar-se dessa forma. Sendo assim, as causas neoplásicas devem ser descartadas. O linfoma não-Hodgkin de células B tipo MALT é o tipo histológico mais comum de linfoma orbitário, as regiões mais frequentemente acometidas são a conjuntiva e glândula lacrimal. No entanto, pode apresentar-se com formas clínicas atípicas, acometendo outras regiões e tecidos.

Descritores: Neoplasias orbitárias; Miosite orbital; Músculos oculomotores; Neoplasias musculares; Linfoma de zona marginal tipo células B; Humanos; Masculino; Adulto; Meia-idade; Relato de caso

\section{INTRODUCTION}

Extraocular muscle disease is typically associated with thyroid disease. However, other rarer etiologies such as neoplasms and infection should also be considered ${ }^{(1-4)}$.

Lymphomas are the most common malignant tumors of the orbit in adults, and the majority of these are secondary to other systemic findings ${ }^{(5,6)}$. On the basis of the classification of the World Health Organization (WHO), and with some modifications from the Revised European and American Lymphoma (REAL) classification, the most common histological type is B-cell lymphoma ${ }^{(6-9)}$. Jakobiec recommended the term B-cell lymphoma of the extranodal marginal zone to indicate the histological subtype of soft tissue tumors located in the orbit. He also suggested that the designation of mucosa-associated lymphoma (MALT) was not appropriate for cases of muscle involvement and should be used only for cases of conjunctival, lacrimal gland, and lacrimal sac area involvement ${ }^{(6)}$.

Certain specific areas such as the conjunctiva, infraorbital tissues, lacrimal system, and extraocular muscles show a good response to treatment and a better prognosis $(63 \%, 58 \%, 28 \%$, and $13 \%$, respectively ${ }^{(1,6,9)}$. Eyelid involvement is related to a worse prognosis ${ }^{(6)}$.

Here we describe the case of a 55-year-old man with orbital non-Hodgkin B-cell MALT lymphoma and emphasize its atypical presentation as medial rectus muscle myositis.

\section{CASE REPORT}

A 55-year-old presented with progressive eye pain and low visual acuity in the right eye since 2 years. His past medical history was unremarkable, and he denied the use of any medications. He had previously undergone treatment for glaucoma in both eyes with travaprost and brimonidine. During the ophthalmologic examination, his visual acuity was 20/70 in the right eye and counting fingers at $1.5 \mathrm{~m}$ in the left eye. The right eye exhibited proptosis (exophthalmometry base $100=31 \mathrm{~mm}$ in the right eye and $14 \mathrm{~mm}$ in the left eye), which was associated with chemosis, conjunctival hyperemia, lower eyelid retraction, exotropia, and ocular motility limitation (Figure 1). There was no palpable regional lymphadenopathy. According to Goldmann tonometry, his intraocular pressure was $32 \mathrm{mmHg}$ in the right eye and $30 \mathrm{mmHg}$ in the left eye. Fundoscopy revealed a cup-to-disc ratio of $0.9 \times$ total in the right eye and $0.7 \times 0.8$ in the left eye, with no other changes. Computed tomography (CT) and magnetic resonance imaging (MRI) of the orbit showed a significantly larger fusiform medial rectus muscle in the right eye, with tendon involvement (Figure 2).

The patient's routine laboratory tests were normal, including thyroid hormones and antibodies. The Mantoux test (purified protein derivative; PPD) was strongly reactive $(22 \mathrm{~mm})$. A biopsy was scheduled, and the hematoxylin-eosin staining of the biopsied tissue showed a relatively homogeneous small cell population with slight
Submitted for publication: October 29, 2013

Accepted for publication: November 7, 2013

Study conducted at Department of Ophthalmology, Universidade Federal de São Paulo (UNIFESP), São Paulo, SP, Brazil.

Department of Ophthalmology, Universidade Federal de São Paulo (UNIFESP), São Paulo, SP, Brazil.
Funding: No specific financial support was available for this study.

Disclosure of potential conflicts of interest: None of the authors have any potential conflicts of interest to disclose.

Corresponding author: Jacqueline M. Sousa. Rua Botucatu, 821 - São Paulo (SP) - 04023-062 Brazil -E-mail: jacmsousa@gmail.com 
nuclear irregularity, inconspicuous nucleoli, and scant cytoplasm ( $\mathrm{Fi}$ gure 3). Immunohistochemistry confirmed non-Hodgkin B-cell MALT lymphoma that was CD20 (+), CD3 (+), cyclin D1 (-), CD5 (-), CD10 (-), CD23 (-), and BCL2 (-) (Figure 4). The patient was referred to the hematology department for systemic staging and treatment.

\section{DISCUSSION}

The extraocular muscles may be involved in several systemic diseases, initially manifesting as orbital myositis. The most common etiology of this pathology in the orbit is Graves'ophthalmopathy, which is an organ-specific autoimmune process with inflammation, edema, and secondary fibrosis. Bilateral symmetric muscle involvement is observed in $70 \%$ patients. The usual pattern of clinical involvement in decreasing order of frequency is as follows: inferior, medial, superior, and lateral muscles ${ }^{(3)}$

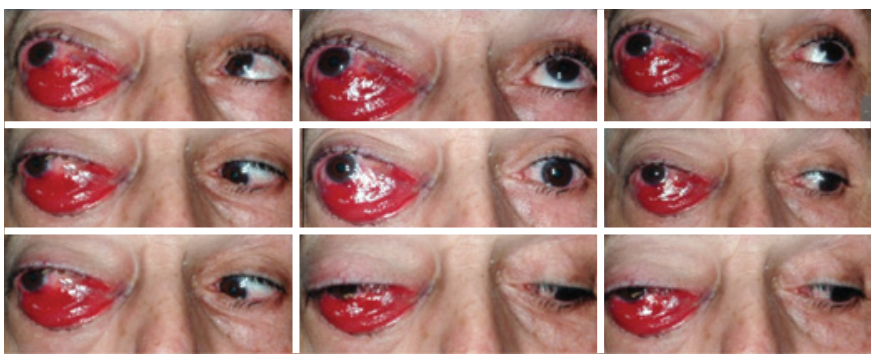

Figure 1. Ectoscopy showing chemosis, conjunctival hyperemia, lower eyelid retraction, exotropia, and limited ocular motility in the right eye.
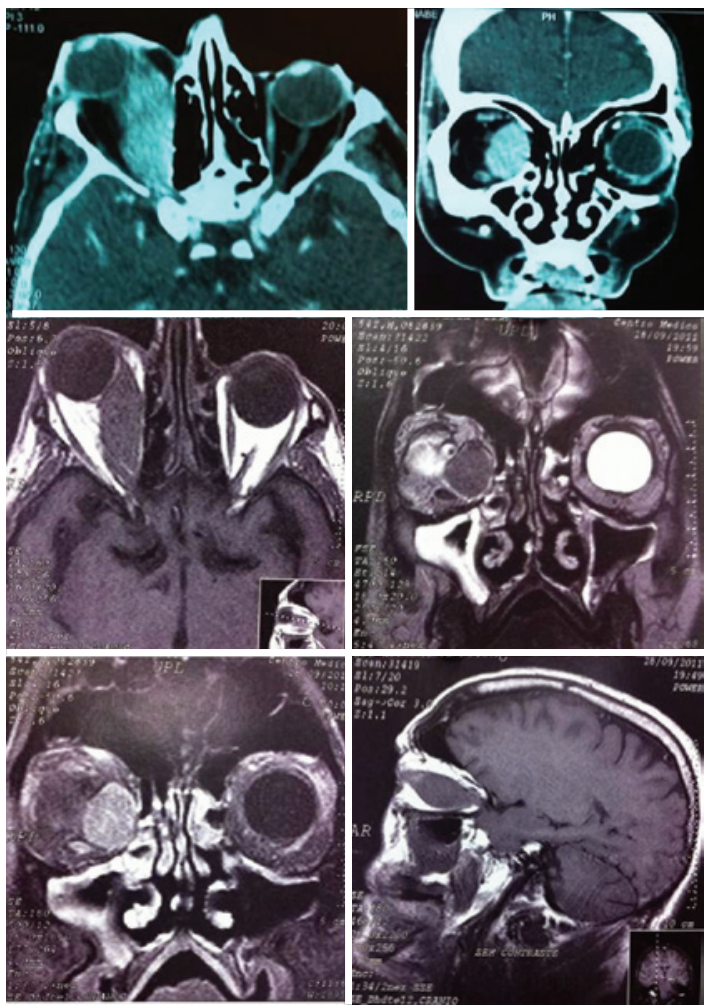

Figure 2. Computed tomography (two photos above) and magnetic resonance imaging (four photos below) of the orbit show that the optic nerve is deflected upward and to the side, with fusiform enlargement of the right medial rectus muscle in full extension, tendon involvement, no damage to the bones of the orbital wall, and no signs of cortical erosion.
In our patient, Graves' ophthalmopathy was the first diagnostic hypothesis according to the history and clinical findings. Therefore, we requested laboratory tests and imaging studies to confirm this hypothesis. Because the thyroid profile and antithyroid antibodies were normal and CT and MRI findings were unremarkable, the hypothesis of Graves' ophthalmopathy became less likely. During our search for the specific etiology, we also considered infectious causes, which are very common in our country. Then, we asked for several serologies and a PPD, which was the only positive test. At that time, our diagnosis was tuberculosis myositis. To confirm this hypothesis and initiate specific treatment, we performed an incisional biopsy, which, to our surprise, revealed non-Hodgkin B-cell MALT lymphoma.

The causes of nonthyroid-related enlargement of the extrinsic muscles are diverse and include inflammatory (idiopathic, sarcoido-

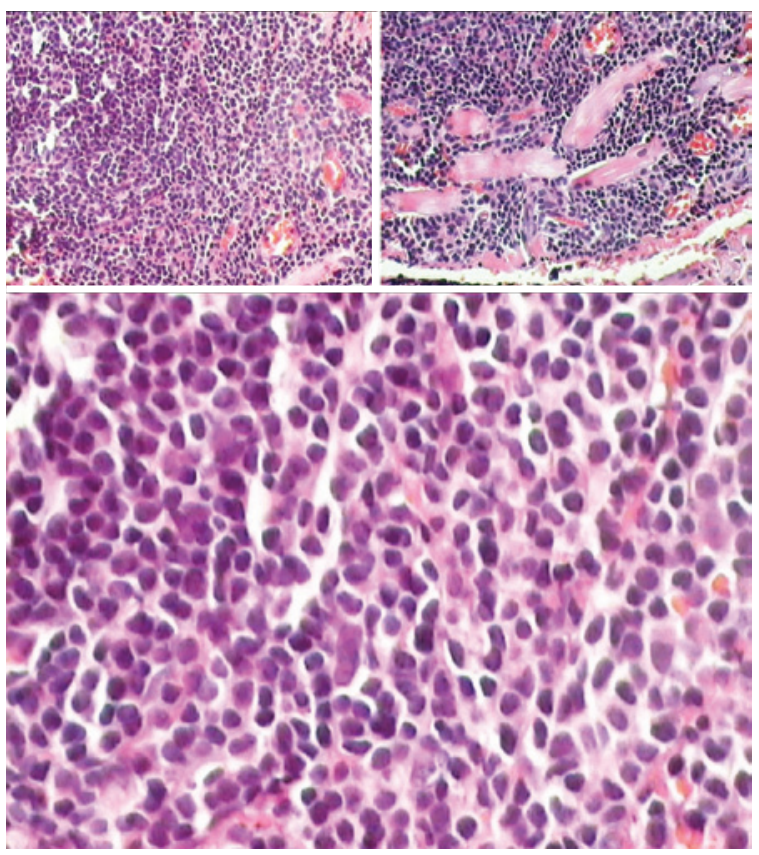

Figure 3. Hematoxylin-eosin staining of the affected rectus muscle shows a relatively homogenous small cell population with slight nuclear irregularity, inconspicuous nucleoli, and scant cytoplasm.

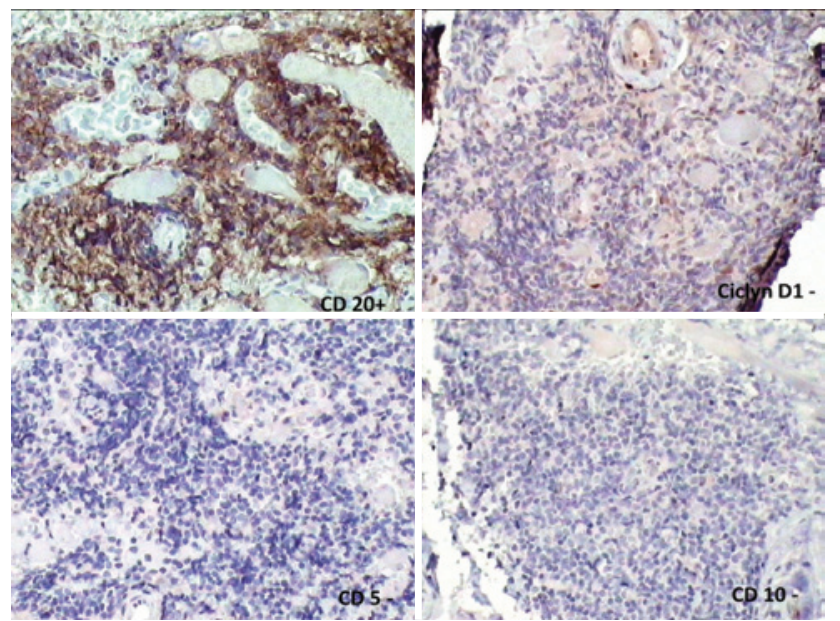

Figure 4. Immunohistochemistry of the biopsied muscle shows CD20 positivity and cyclin D1, CD5, and CD10 negativity. 
sis, Crohn's disease, systemic lupus erythematosus, rheumatoid arthritis, and Wegener's granulomatosis), vascular (carotid-cavernous fistula and arteriovenous malformation), neoplastic (metastatic, secondary or primary), infectious (secondary to orbital cellulitis or primary), deposition-related (amyloid), traumatic, and iatrogenic causes ${ }^{(3)}$. Despite its rare occurrence, orbital lymphomas should be considered in the differential diagnosis of this type of condition ${ }^{(3)}$. Another rare etiology that should be considered, particularly in endemic regions such as Brazil, is myositis caused by tuberculosis ${ }^{(4)}$.

Lymphomas with the presentation of myositis and no other symptoms are very rare in the scientific literature. The largest series of ocular adnexal lymphomas described in the scientific literature (353 cases) do not describe this type of clinical presentation. There have been few revisions or only isolated case reports ${ }^{(1,2,5,7-9)}$. Different authors have mentioned diplopia, periorbital inflammation, restriction of motility, and proptosis as the main clinical findings $s^{(1,5,7-9)}$. Such symptomatology may suggest the impairment of ocular muscles. Watkins et al. and Lacey et al. mention that the upper muscles are more frequently involved, particularly the superior rectus and the superior oblique muscles, respectively ${ }^{(1,3)}$. Lacey et al. also determined that the disease is usually unilateral, describing only one patient with symmetrical bilateral infiltration ${ }^{(3)}$. In our patient, there was unilateral involvement of the medial rectus muscle, as observed in the case described by Rossman et al. ${ }^{(2)}$. Histologically, the muscle involvement is mainly nodular and does not spare the tendons $s^{(1,3)}$.

The clinical presentation of non-Hodgkin B-cell MALT Iymphoma or extranodal marginal zone lymphoma in the orbit is indolent with a low risk of progression in the bone marrow, indicating a good prognosis in most cases ${ }^{(2,3)}$. Our patient was symptomatic for 2 years and had no metastasis, emphasizing the indolent course of the disease.

Imaging studies such as CT and MRI allow for the observation of the increased thickness of the affected muscle and tendon involvement. This information, together with the clinical signs and pathology, can confirm the diagnosis. In our patient, imaging studies revealed tendon involvement, which suggested a differential diagnosis of Graves' ophthalmopathy. In imaging studies, other characteristics of thyroid ophthalmopathy that may be observed include well-defined fusiform enlargement of the muscle (especially posteriorly) with smooth borders, no tendon enlargement, normal orbital fat, preseptal edema, and lacrimal gland prolapse ${ }^{(3)}$.

Confirmation of the diagnostic biopsy with immunohistochemistry is essential, and the usual findings are as follows: CD 20 (+), CD 43
(+), BCL $6(-)$ MUM1 (-), p16 (+), p21 (-), pRB (-) p53 (-), and cyclin D1 $(-)^{(3)}$. Our patient was CD $20(+), \operatorname{CD} 10(-), \operatorname{CD} 23(-), \mathrm{BCL} 2(-)$, and cyclin D1 (-) in B-cells and CD3 (+) and CD 5 (+) in T-lymphocytes. Genetically, the translocations most frequently encountered are $t(3 ; 14)$ (p14.1;q32) involving FOXP1 and IgH and $t(14 ; 18)(q 32 ; q 21)$ involving IgH and MALT ${ }^{(6,10)}$.

When the diagnosis of non-Hodgkin B-cell MALT lymphoma was established, we immediately sent the patient to the Hematology department of UNIFESP for treatment. Multidisciplinary evaluation and systemic staging was mandatory because of good response to treatment and good prognosis.

In conclusion, the findings from our case indicate that it is important to consider lymphoma as one of the differential diagnoses in cases of isolated myositis, although Graves' ophthalmopathy should continue to be the first diagnosis to be considered.

\section{REFERENCES}

1. Watkins LM, Carter KD, Nerad JA. Ocular adnexal lymphoma of the extraocular muscles: case series of the University of lowa and review of the literature. Ophthal Plast Reconstr Surg. 2011;27(6):471-6.

2. Rossman D, Michel R, Codere F. A case of an enlarged medial rectus muscle. Int Ophthalmol. 2009;29(4):319-21.

3. Lacey B, Chang W, Rootman J. Nonthyroid causes of extraocular muscle disease. Surv Ophthalmol. 1999;44(3):187-213.

4. Wang JY, Lee LN, Hsueh PR, Shih JY, Chang YL, Yang PC, et al. Tuberculous myositis rare but existing clinical entity. Rheumatology (Oxford). 2003;42(7):836-40.

5. Ferry JA, Fung CY, Zukerberg L, Lucarelli MJ, Hasserijan RP, Preffer FI, et al. Lymphoma of the ocular adnexa: a study of 353 cases. Am J Surg Pathol. 2007;31(2):170-84.

6. Jakobiec FA. Ocular adnexal lymphoid tumors: progress in need of clarification. Am J Ophthalmol. 2008;145(6):941-50. Comment on: Am J Ophthalmol. 2008;145(6):1002-6.

7. Coupland SE, Hellmich M, Auw- Haedrich C, Lee WR, Stein H. Prognostic value of cell-cycle markers in ocular adnexal lymphoma: an assessment of 230 cases. Arch Clin Exp Ophtalmol. 2004;242(2):130-45

8. Coupland SE, Krause L, Delecluse HJ, Anagnostopoulos I, Foss HD, Hummel M, et al. Lymphoproliferative lesions of the ocular adnexal: analysis of 112 cases. Ophthalmology. 1998;105(8):1430-41.

9. Lagoo AS, Haggerty C, Kim Y, Hammons M, Neufeld K, Redher C, et al. Morphologic features of 115 lymphomas of the orbit and ocular adnexa categorized according to the WHO classification: are marginal zone lymphomas in the orbic mucosa-associated lymphoid tissue type lymphomas? Arch Pathol Lab Med. 2008;132(9):1405-16.

10. Takada S, Yoshino T, Taniwaki M, Nakamura N, Nakamine H, Oshima K, et al. Involvement of the chromosomal translocation $\mathrm{t}(1 ; ; 18)$ in some mucosa-associated lymphoid tissue lymphomas and diffuse large B-cell lymphomas of the ocular adnexa: evidence from multiplex reverse transcriptase-polymerase chain reaction and fluorescence in situ hybridization on using formalin-fixed, paraffin-embedded specimens. Mod Pathol. 2003;16(5):445-52. 